This section looks back to some ground-breaking contributions to public health, reproducing them in their original form and adding a commentary on their significance from a modern-day perspective. John C. Caldwell reviews the 1971 paper by Abdel Omran on the epidemiological transition. Extracts from the original paper are reproduced, by permission, from The Milbank Memorial Fund Quarterly.

\title{
Population health in transition
}

\author{
John C. Caldwell ${ }^{1}$
}

Until recent times most deaths were caused by infectious diseases, degenerative diseases, or violence. Let us ignore violent deaths, as they can occur at any age. Infectious diseases are a threat from the day of birth and, indeed, the very young are most susceptible to their attack. People die of degenerative diseases at older ages because it usually takes time for the body to degenerate and there is little else to die from, though they must eventually die of something. What happened in the mortality transition was the conquest of infectious disease, not a mysterious displacement of infection by degeneration as the cause of death. The resulting demographic transition with its changing age of death and the existence of large numbers of people afflicted with chronic degenerative disease (rather than life-threatening infectious disease) is important for planning health services and medical training, which is the current focus of the burden of disease approach.

Why did Abdel Omran's essay (1) have such an impact on the public health community, an impact with echoes of Malthus's views on population? There are certain similarities to The First Essay of Malthus in 1798: Omran firmly stated a number of propositions, which were only sparingly spelled out and buttressed by limited references. Also, he republished the paper several times although, unlike Malthus, his additions were largely limited to applying the thesis to the United States and suggesting a fourth stage (2). Omran postulated the displacement of pandemics by "degenerative and manmade diseases" without explaining what was meant by the latter, but in 1982 he specified that it included "radiation injury, mental illness, drug dependency, traffic accidents, occupational hazards" (2).

The public health community was undoubtedly attracted by the prospect of combating man-made diseases: what human activity could create, human activity could correct. The other attraction was the suggestion that somehow degenerative and man-

\footnotetext{
${ }^{1}$ Coordinator, Health Transition Centre, National Centre for Epidemiology and Population Health, Australian National University, Canberra, ACT 0200, Australia.
}

Ref. No. 00-0828 made diseases had replaced infectious ones, which presented a picture of combat between warring camps of disease into which the health professionals could throw themselves. Omran did in places relate this replacement to mortality decline and changing age structures, though he touched upon age structure only very lightly and usually treated a population as an undifferentiated unit. This approach was central in giving the paper such force.

Omran added strength to his argument by segmenting the epidemiological transition into periods with different mortality patterns and disease levels. Thomas McKeown also did this, though only his first two historical papers $(3,4)$ were published before Omran's.

The other form of segmentation Omran used was numbered propositions, to which we now turn. Proposition One, "that mortality is a fundamental factor in population dynamics", has always been agreed: in all demographic transition theories it is the prior decline in mortality that in due course precipitates the fertility decline. It is true that for decades after the Second World War demographers gave more attention to the causes and nature of the fertility decline than to those of the mortality decline, though they stressed that such attention was necessary because of the preceding unforeseen steep mortality decline in developing countries. The importance of Omran's and McKeown's work is that they drew attention to this imbalance.

The core of Proposition Two, "During the transition, a long-term shift occurs in mortality and disease patterns" is clear, but the subsequent excursion into the determinants of the transition is subject to the same criticisms as have been levelled at McKeown's work. The ascription of the 19th-century Western mortality decline primarily to ecobiological and socioeconomic factors (McKeown said nutrition), the argument that "the influence of medical factors was largely inadvertent", and the implication that the struggle against infectious disease was unimportant after the turn of the century, are all contestable. These conclusions were largely drawn from the mortality statistics of Sweden and England and Wales. The problem with relegating the 20 th century to unim- 
portance is that it accounts for $66 \%$ of the total mortality decline between 1800 and 1971 in England and Wales and 54\% in Sweden, much of which can probably be attributed to the reduction in infectious diseases. There are also difficulties about 19thcentury chronology. In both countries mortality fell quite rapidly between 1800 and 1840, more slowly between 1840 and 1870 (in England hardly at all), and fastest in the last three decades of the century. The improvement between 1800 and 1840 may have been partly propelled by improvements in personal hygiene. Of the ensuing mortality decline from 1840 to the end of the century, $86 \%$ in England and Wales and 67\% in Sweden occurred after 1870. This was the period when advances were made in the treatment of water, the provision of sanitary services, the removal of waste, and the enforcement of laws against overcrowding. Antiseptics began to be used and, towards the end of the century, pasteurization, especially in the form of the home boiling of milk for babies. Doctors may have had only limited curative powers but they appear to have given leadership in improving hygiene, midwifery training and child care. On the other hand there is little evidence that nutrition improved (2). Even the limited 18thcentury mortality decline can probably be at least partly explained by more effective government action to reduce famine mortality peaks (5), and perhaps also - employing findings from the contemporary Third World - by the growth of the market and transport networks (๑).

Proposition Three is that "During the epidemiologic transition the most profound changes in health and disease patterns obtain among children and young women". Certainly mortality rates fell fastest for most of the transition among children ( 7 ). It is not clear why Omran placed an equal stress on women, though in many countries female mortality falls in the reproductive ages as fertility declines, and men in the West damaged their health to a greater extent than women during the cigarette smoking "epidemic" that began with the First World War.

Proposition Four is that "The shifts in health and disease patterns that characterize the epidemiologic transition are closely associated with the demographic and socioeconomic transition that constitute the modernization complex". It is plausible to argue that these shifts are the mortality side of the demographic transition. They are all, of course, the result of global economic growth and modernization. But expressing the change as being essentially socioeconomic subtly downgrades the specific contributions made by public health interventions and especially by breakthroughs in medical science. This suspicion receives powerful support from the extraordinary pot-pourri that constitutes Table 4, where everything that has happened to Western society is thrown together as if all of it had causal relationships. This table and the accompanying account of consumption output ratios break the lucidity of the developing argument and do little to enhance it.

Proposition Five, with its three basic models of the epidemiological transition, fails to grasp the global nature and the historical sequence of the mortality transition as it spread. In truth, there are probably as many models as there are societies. It underestimates the flow around the world of ideas, behavioural models, education systems, public health approaches and medical technologies. Both Omran and others were tempted to add further stages, particularly a stage associated with the reduction of age-specific death rates of degenerative diseases and the accompanying increase in life expectancy at older ages $(2,8)$.

Omran's essay, together with the work of McKeown, makes the case for a greater concentration on the mortality side of demographic transition. It saw health change as part of social change, and led public health practitioners to regard their activities as of central importance. On the other hand, Omran seemed to argue that the change in the causes of death was a determinant rather than a consequence. His theory could be attacked as being insufficiently epidemiological in that its focus was the changing causes of death rather than the changing causes of patterns of illness. It seems so determined to emphasize the role of social change and, to some extent, ecobiological and environmental change, that it goes out of its way to understate the contributions of scientific inquiry and medical technology, in spite of their also being products of the modernization process. Few concessions are made to the roles of laboratory experimentation in showing how water can be purified, sewage made safer, and immunization programmes rendered possible; of doctors in giving leadership in the 19th century; or of curative medicine at any time. Its greatest value was to stimulate inquiry.

\section{References}

1. Omran AR. The epidemiologic transition: a theory of the epidemiology of population change. Milbank Memorial Fund Quarterly, 1971, 29: 509-538.

2. Omran AR. Epidemiologic transition. In: Ross JA, ed., International encyclopedia of population. London, The Free Press, 1982: 172-183.

3. McKeown T, Brown RG. Medical evidence related to English population changes in the eighteenth century. Population Studies, 1955, 9: 119-141.

4. McKeown T, Record RG. Reasons for the decline in mortality in England and Wales during the nineteenth century. Population Studies, 1962, 16: 94-122.
5. Flinn MW. The stabilization of mortality in pre-industrial Western Europe. Journal of European Economic History, 1974, 3: $285-318$.

6. Caldwell JC. The Sahelian drought and its demographic implications. Washington, DC, Overseas Liaison Committee, American Council on Education, 1975.

7. Caldwell P. Child survival: physical vulnerability and resilience in adversity in the European past and the contemporary Third World. Social Science and Medicine, 1996, 43: 609-619.

8. Olshansky SJ, Ault AB. The fourth stage of the epidemiologic transition: the age of delayed degenerative diseases. Milbank Memorial Fund Quarterly, 1986, 64: 355-391. 


\title{
THE MILBANK MEMORIAL FUND QUARTERLY
}

\author{
1971, 49(4): 509-538.
}

THE EPIDEMIOLOGIC TRANSITION

A Theory of the Epidemiology of Population Change

\section{ABDEL R. OMRAN}

Although demography continues to be the most prominent discipline concerned with population dynamics, involvement of other disciplines is highly desirable. The case for a multidisciplinary approach to population theory has been aptly stated by Kurt Mayer: "Any meaningful interpretation of the cause and effects of population changes must ... extend beyond formal statistical measurement of the components of change, i.e. fertility, mortality and migration, and draw on the theoretical framework of several other disciplines for assistance." ${ }_{1}$...

A theory of epidemiologic transition, sensitive to the formulations of population theorists who have stressed the demographic, biologic, sociologic, economic and psychologic ramifications of transitional processes, was conceived by this author less than four years ago. Recognition of the limitations of demographic transition theory and of the need for comprehensive approaches to population dynamics stimulated the development of this theory. ${ }^{2}$

\section{FOCUS OF THE THEORY OF EPIDEMIOLOGIG TRANSITION}

Conceptually, the theory of epidemiologic transition focuses on the complex change in patterns of health and disease and on the interactions between these patterns and their demographic, economic and sociologic determinants and consequences. An epidemiologic transition has paralleled the demographic and technologic transitions in the now developed countries of the world and is still underway in less-developed societies. Ample evidence may be cited to document this transition in which degenerative and man-made diseases displace pandemics of infection as the primary causes of morbidity and mortality.

The major precepts of the theory of epidemiologic transition are presented below. Smoothed data from the United Nations Model Life Tables, ${ }^{3}$ representing a "pooled" cross-cultural view of mortality patterns at various life expectancy levels, provides a useful introduction to the basic propositions.* The longitudinal view added by historical and contemporary data from several countries provides further documentation; data from individual countries also serve to illustrate some of the peculiar variations

*Data for the U.N. Model Life Tables are gathered from a number of countries around the
world, with some unavoidable over-representation of countries that are now developed because world, with some unavoidable over-representation of countries that are now developed because
their vital statistics are more complete and more accurate than those for less developed countries.

of the transition and to support three models that differentiate distinctive patterns of the epidemiologic transition. These models are the Classical or Western Model, as represented here by England and Wales and Sweden; the Accelerated Transition 
Model, as represented by Japan; and the Contemporary or Delayed Model as represented by Chile and Ceylon....

\section{MORTALITY AND POPULATION DYNAMIGS}

Proposition One: The theory of epidemiologic transition begins with the major premise that mortality is a fundamental factor in population dynamics. The clearest indication of mortality's dominant role in population dynamics is implicit in theories of population cycles. The cyclic rises and falls in population size that have been observed in animal and pre-modern human populations reflect sequential phases of population growth and decline; disregarding the possible selective influences of migration, these cyclic movements must ultimately be accounted for in terms of the range of variation in fertility and mortality. ..

No secular downward trend in mortality is apparent in any country before the middle of the eighteenth century, about the same time that population growth began to demonstrate an exponential curve. The initial period of sustained population growth in nearly every country for which reliable data are available corresponds with at least two decisive changes in the death rate. First the fluctuations in mortality became less frequent and less drastic. Second, the initial, slow-sometimes imperceptible-decline in mortality gradually gained momentum and eventually stabilized at relatively low levels in the twentieth century. Thus steady rises in life expectancy, progressively diminishing death rates and more stable and predictable mortality patterns have accompanied the persistent increments in world population....

Demographic trends for England and Wales, Japan, Ceylon and Chile are compared in Figure 2. In each country an exponential pattern of population growth accompanies the secular downward trend in mortality. In England and Wales, where the transition from high to low vital rates occurred over two centuries, the exponential growth curve was attenuated only after fertility fell and approached the low level of mortality; this pattern is less apparent for Japan, where an accelerated transition occurred over several decades. Although data concerning the relative effects of mortality and fertility on population growth are incomplete for the early transitional period, it seems likely that a significant though temporary increase in fertility may have added momentum to the population explosion set off by steady improvements in survivorship. The influence of fertility is particularly apparent in the rapid population growth of currently developing nations that have not yet completed their transitions; see for example the graphs for Chile and Ceylon in Figure 2. In most of these developing countries, the death rate has declined rapidly in recent years, especially since World War II, and the birth rate has remained high with minor fluctuations. This sudden widening of the demographic gap has produced unprecedentedly high rates of population growth, as can be seen by comparing the growth curves of the four countries in Figure 2.

\section{SHIFTS IN MORTALITY AND DISEASE PATTERNS}

Proposition Two: During the transition, a long-term shift occurs in mortality and disease patterns whereby pandemics of 
FIGURE 2. DEMOGRAPHIC TRENDS IN SELEGTED GOUNTRIES
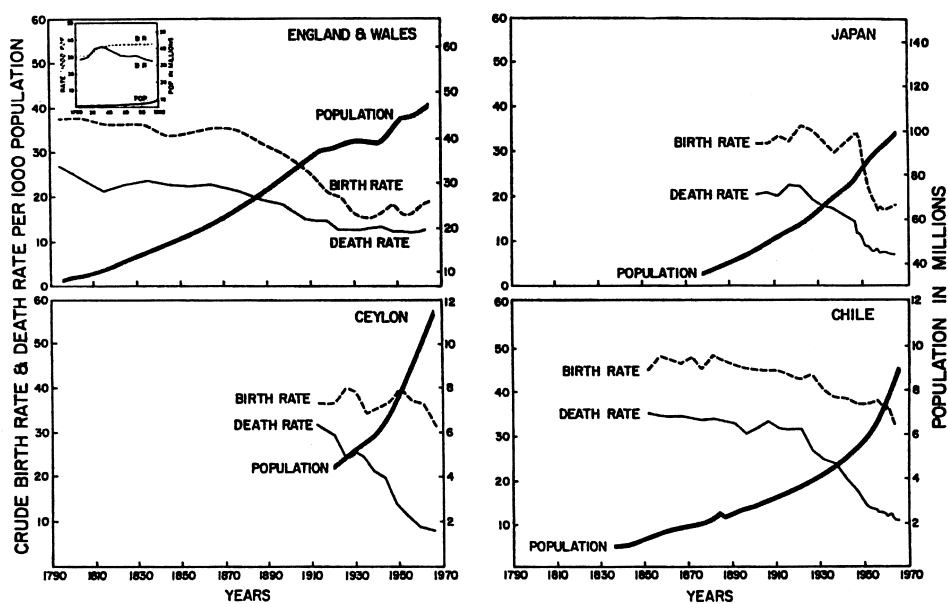

Sources: England and Wales eighteenth century data (inset) and early nineteenth century data (to 1841) are Brownlee's estimates, cited by Glass, D. V., Population and Population dovements in England and Wales, 1700 to 1850, in Glass, D." P. and Eversley, D. E. C. (Editors), POPULATION IN HISTORY, Chicago, Aldine Publishing Company, 1965, pp. 221-246;
data for 1841-50 and 1951-55 are from Glass, D. and Grebenik, E., World Population, 1800-

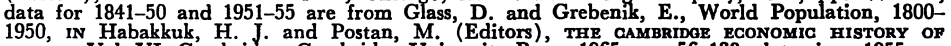

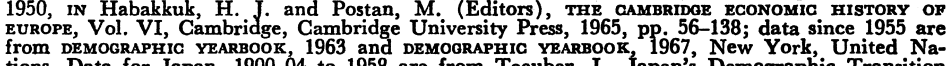
tions. Data for Japan, 1900-04 to 1958 are from Taeuber, II, Japan's Demographic Transition
Re-examined, Population Studies, 14, 28-39, 1960-61; data since 1958 from DEMOGRAPHIC YEARBOOK, op. cit. Data for Chile, 1850-54 to 1960-64, are from Collver, O. A., BIRTH RATES IN LATIN AMRRICA: NEW ESTIMATES OF HISTORICAL TRENDS AND FLUCTUATIONS, Research Series No. 7. Berkeley, Institute of International Studies, University of California, 1965; data since 1962 national Vital Statistics, Vital Statistics Special Reports, 9 , May 2, 1940; 1936 -38 to 1946 data from ANNUAL EPIDEMIOLOGIG AND VITAL STATISTICS, 1939-1946, Geneva, World Health Organization, 1951; data since 1947 from DEMOGRAPHIC YEARBOOK, 1953, 1963, and 1967, op. cit.

infection are gradually displaced by degenerative and man-made diseases as the chief form of morbidity and primary cause of death. Typically, mortality patterns distinguish three major successive stages of the epidemiologic transition:

1. The Age of Pestilence and Famine when mortality is high and fluctuating, thus precluding sustained population growth. In this stage the average life expectancy at birth is low and variable, vacillating between 20 and 40 years.

2. The Age of Receding Pandemics when mortality declines progressively; and the rate of decline accelerates as epidemic peaks become less frequent or disappear. The average life expectancy at birth increases steadily from about 30 to about 50 years. Population growth is sustained and begins to describe an exponential curve.

3. The Age of Degenerative and Man-Made Diseases when mortality continues to decline and eventually approaches stability at a relatively low level. The average life expectancy at birth rises gradually until it exceeds 50 years. It is during this stage that fertility becomes the crucial factor in population growth.

The Age of Pestilence and Famine represents for all practical purposes an extension of the pre-modern pattern of health and disease. In this stage the major determinants of death are the malthusian "positive checks," namely, epidemics, famines and wars. ...

The gradual shift in disease patterns characteristic of the classical transition can be seen in the steady decline of infectious diseases (including tuberculosis and diarrhea) and the moderate increase in cancer and cardiovascular diseases in England and Wales up to 1920. After World War I, the decline of infectious and rise of degenerative diseases is more distinct, and since 1945 the increase in cardiovascular deaths is particularly strik- 
ing. The shift from infectious to degenerative disease predominance is more readily apparent for Japan, which has experienced an accelerated transition in only a few decades. Among currently developing nations, the transition from infectious to degenerative disease predominance has started but has not yet been completed....

The recession of infectious diseases that began in Chile in the 1920's has been gradual but discernible. In Ceylon this shift was delayed even further until the late 1940's.

The determinants of the transition from infectious to degenerative disease predominance are by no means simple. Their detailed treatment is beyond the scope of this paper; however, it may be useful to mention three major categories of disease determinants.

1. Ecobiologic determinants of mortality indicate the complex balance between disease agents, the level of hostility in the environment and the resistance of the host. More often than not, however, even these determinants cannot be categorically specified. One outstanding example is the recession of plague in most of Europe toward the end of the seventeenth century. The reasons for this recession are not fully understood, although the mysterious disappearance of the black rat may have been a contributing factor. Nonetheless, it is relatively certain that with the possible exception of smallpox, the recession of plague and many other pandemics in Europe was in no way related to the progress of medical science. ${ }^{16}$

2. Socioeconomic, political and cultural determinants include standards of living, health habits and hygiene and nutrition. Hygiene and nutrition are included here, rather than under medical determinants because their improvement in western countries was a byproduct of social change rather than a result of medical design.

3. Medical and public health determinants are specific preventive and curative measures used to combat disease; they include improved public sanitation, immunization and the development of decisive therapies. Medical and public health factors came into play late in the western transition, but have an influence early in the accelerated and contemporary transitions.

The reduction of mortality in Europe and most western countries during the nineteenth century, as described by the classical model of epidemiologic transition, was determined primarily by ecobiologic and socioeconomic factors. The influence of medical factors was largely inadvertent until the twentieth century, by which time pandemics of infection had already receded significantly. The mortality decline in currently developing countries has been more recent and the effect of medical factors has been more direct and more salient, as shown by the contemporary or delayed transition model. In the AfroAsian countries in particular, the tremendous impact of imported medical technologies on mortality has been magnified by massive public health programs. Although it would be naive to attempt precise identification of the complex determinants in each case, it does seem apparent that the transition in the now developed countries was predominantly socially determined, whereas the transition in the "third world" is being significantly influenced by medical technology. 
Proposition Three: During the epidemiologic transition the most profound changes in health and disease patterns obtain among children and young women. The genuine improvements in survivorship that occur with the recession of pandemics are peculiarly beneficial to children of both sexes and to females in the adolescent and reproductive age periods, probably because the susceptibility of these groups to infectious and deficiency diseases is relatively high.

Childhood survival is significantly and progressively improved as pandemics recede in response to better living standards, advances in nutrition and early sanitation measures and is further enhanced as modern public health measures become available. ...

Although all age groups benefit from the shift in disease patterns and the increase in life expectancy, the decline in childhood mortality is demonstrably the greatest, especially in the one to four year age group....

\section{INTERAGTING TRANSITION VARIABLES}

Proposition Four: The shifts in health and disease patterns that characterize the epidemiologic transition are closely associated with the demographic and socioeconomic transition that constitute the modernization complex.

\section{Interactions with Demographic Changes}

The decline in mortality that comes with the epidemiologic transition widens the "demographic gap" between birth rates and death rates and hence affects demographic change by bolstering population growth (see Figure 2). In a more subtle manner, the mortality transition affects demographic movements indirectly through its impact on fertility and population composition...

Because the probability of a female surviving the reproductive period usually increases earlier in the transition than improvements in infant and childhood survival, fertility may rise in the early stage of the epidemiologic transition. The tendency of improved infant and childhood survival to depress fertility in the middle and subsequent stages of the transition can be attributed largely to the following factors:

1. Biophysiologic factors: The increased chance that a live birth will survive infancy and early childhood and result in prolonged lactation tends to lengthen the mother's postpartum period of natural protection against conception. Another run of the REPSIM model, which simulated both long and short postpartum periods as a function of the probable pregnancy outcome, shows a moderately declining net reproduction rate at higher life expectancy levels. These data also indicate that the interval between births increases progressively at all parities as life expectancy rises. Ridley, et al., concluded that the lengthening of birth intervals, particularly among young, highly fecund, low-parity women, has a deflationary effect on ultimate parity and is a major mechanism linking improved survival and lowered fertility.

2. Socioeconomic factors: The risk of childhood death is lowered by better nutrition and sanitation as socioeco- 
nomic conditions improve. As the probability of child survival increases, the desirability of having many children may diminish in response to changes in the social and economic system that cast the child as an economic liability rather than asset. Concomitantly, improvements in birth control technology facilitate the achievement of emerging small family size norms.

3. Psychologic or emotional factors: Improved infant and childhood survival tends to undermine the complex social, economic and emotional rationale for high parity for individuals and hence high fertility for society as a whole. As couples become aware of the near certainty that their offspring, particularly a son, will survive them, the likelihood of practicing family limitation is enhanced. Not only are compensatory efforts to "make up" for lost children reduced, but the investment of parental energies and emotions may take on a new, qualitative dimension as each child in the small family is provided better protection, care and education....

\section{BASIC MODELS OF THE EPIDEMIOLOGIC TRANSITION}

Proposition Five: Peculiar variations in the pattern, the pace, the determinants and the consequences of population change differentiate three basic models of the epidemiologic transition: the classical or western model, the accelerated model and the contemporary or delayed model. Through the description, analysis and comparison of mortality patterns in many societies and at different points in time, distinctive core patterns of the epidemiologic transition emerge. The fundamental purpose of delineating these models is to visualize the different matrices of determinants and consequences associated with mortality (and fertility) patterns and to elucidate some of the fundamental issues confronting population policy-makers. As illustration, three models of the epidemiologic transition are sketched below.

\section{The Classical (Western) Model of Epidemiologic Transition}

The Classical model describes the gradual, progressive transition from high mortality (above 30 per 1,000 population) and high fertility (above 40 per 1,000) to low mortality (less than 10 per 1,000 ) and low fertility (less than 20 per 1,000 ) that accompanied the process of modernization in most western European societies. Following a stage of pestilence and famine that prevailed during the pre-modern and early modern periods, a slow unsteady rate of mortality decline gradually gave way to more precipitous declines around the turn of the twentieth century, by which time fertility had already turned downward. Some of the major changes in the population, and in the economic, social and health profiles that occurred in the classical transition are given in capsule form in Table 4 ....

\section{The Accelerated Epidemiologic Transition Model}

The Accelerated Epidemiologic Transition model describes the accelerated mortality transition that occurred most notably in Japan. Both the fluctuating mortality in the Age of Pestilence and Famine and the gradual (early) phase of the Age of Receding Pandemics followed a pattern similar to, though later than, the classical model. A major distinction of the accelerated 
model is that the period taken for mortality to reach the 10 per 1,000 level was much shorter than that for the classical model, as can be seen by comparing the graphs for England and Wales and Japan in Figure 2. The shift to the Age of Degenerative and Man-made Diseases was also much faster....

\section{The Contemporary (or Delayed) Epidemiologic Transition Model}

The Contemporary model describes the relatively recent and yet-to-be completed transition of most developing countries. Although slow, unsteady decline in mortality began in some of these countries shortly after the turn of the century, rapid and truly substantial declines in mortality have been registered only since World War II. Public health measures have been a major component of the imported, internationally sponsored medical package that has played a decisive role in setting the stage for astronomic population growth in these economically handicapped countries. In other words, these programs have successfully manipulated mortality downward while leaving fertility at substantially high levels. Both national and international programs of "population control" designed to hasten fertility decline artificially are prominent features of this model for countries where death control has far outstripped birth control. Despite unmistakable gains in the survival of women and children, infant and childhood mortality remains excessively high in most of these countries and in some, females of reproductive age continue to have higher mortality risks than males in the same age group. Although most countries in Latin America, Africa and Asia fit this model, important differences between these areas suggest the utility of developing submodels, particularly with regard to the varying responses of fertility and socioeconomic conditions to national development programs.

\section{SUMMARY}

Despite the inherent difficulties in attempting to structure a matrix that includes all the complex vital factors of population dynamics, the need to do so is urgent. A vast array of social, economic and demographic as well as epidemiologic factors shape the course of population change, and although it is doubtful that one comprehensive, all inclusive population theory will ever be formulated, scholars in various disciplines will continue to develop and refine segments of the theory.

The theory of epidemiologic transition, which has been sketched in this brief essay, represents the continuing efforts of this author to crystallize the mechanisms of interaction that characterize the patterns, determinants and consequences of health and disease changes in a variety of social contexts. The basic strategy is not only to describe and compare the mortality transitions of various societies, but more importantly, to lend theoretical perspective to the process of population change by relating mortality patterns to demographic and socioeconomic trends-both longitudinally and cross-sectionally-through the development of models. With elaboration and refinement of such models, comparative analyses of the epidemiologic transition in various population groups can provide information needed to treat at least some of the many problems associated with disequilibrating population movements. 


\section{TABLE 4. The classical (western) model of the epidemiologic transition}

\begin{tabular}{|c|c|c|}
\hline TRANSITION PROFILES & AGE OF PESTILENCE AND FAMINE & $\begin{array}{c}\text { AGE OF RECEDING PANDEMICS } \\
\text { EARLY PHASE }\end{array}$ \\
\hline \multicolumn{3}{|l|}{ POPULATION PROFILE } \\
\hline Population Growth & $\begin{array}{l}\text { The pattern of growth until about } 1650 \text { is cyclic, with minute net } \\
\text { increments; mortality dominates with crude death rates of from } 30 \text { to more } \\
\text { than } 50 / 1000 \text { and with frequent higher peaks. Fertility is at a sustained high } \\
\text { level of } 40 \text { or more per } 1000 \text {. }\end{array}$ & $\begin{array}{l}\text { Mortality continues high }(30-50+/ 1000) \text { but peaks are } \\
\text { less frequent and the general level begins declining. } \\
\text { Fertility remains high }(40+/ 1000) \text {. The demographic gap } \\
\text { widens somewhat, and there is a net population increase } \\
\text { which, though small, is cumulative. }\end{array}$ \\
\hline Population Composition & $\begin{array}{l}\text { The population is predominantly young, with very large young and very } \\
\text { small old dependency ratios, and a slight excess of males ( } 100+\mathrm{M} / 100 \mathrm{~F}) \text {. } \\
\text { Residence is mainly rural with a few crowded, unsanitary, war-famine- } \\
\text { epidemic ridden cities of small or medium size. }\end{array}$ & $\begin{array}{l}\text { The population is still young, though the proportion of } \\
\text { older people begins to increase. The male-female ratio is } \\
\text { near unity (100M/100F). Residence is still primarily rural } \\
\text { but with a progressive exodus from farm to factory. } \\
\text { Selective migration to new colonies relieves population } \\
\text { pressure somewhat in home countries but upsets the age- } \\
\text { sex composition. }\end{array}$ \\
\hline ECONOMIC PROFILE & $\begin{array}{l}\text { Subsistence economies characterize predominantly agrarian societies which } \\
\text { depend on manual, labor-intensive production methods. Occasional } \\
\text { breakthroughs and sporadic rises in wages are largely undermined by } \\
\text { low incentives and cosmic catastrophes, while labor efficiency is marred by } \\
\text { debilitative and enervative diseases. }\end{array}$ & $\begin{array}{l}\text { Preconditions for economic "take-off" appear: Improve- } \\
\text { ments in agriculture and land-use coupled with modest } \\
\text { development of transportation-communication networks } \\
\text { encourage industrialization; leading sectors of production, } \\
\text { e.g. textiles and lumber, emerge. }\end{array}$ \\
\hline
\end{tabular}

SOCIAL PROFILE

Society

Family and Women

Living Standards

Food and Nutrition
Society is traditional, with a fatalistic orientation sustained by rigid, hierarchical socio-political structures.

Clan or extended family structures with large family size, multiple generation households, and home-centered life styles are dominant. Women are cast strictly in the mother role with virtually no rights or responsibilities outside the home.

Standards are very low; grossly unsanitary conditions prevail at both the public and private levels, and comforts and luxuries are limited to a few elites.

Food available to the masses is of poor quality, with chronic and occasionally acute shortages. Children and women in the fertile years are most adversely affected.
A traditional/provincial outlook persists among the lower classes while the upper and emerging middle classes of businessmen adopt "faith in reason."

Extended family systems and large family size still prevail. The maternal role begins to allow a little involvement in such areas as home crafts.

Standards are still quite low but there is some improvement toward the end of the period.

Early improvement in agriculture and crop rotation and increased use of the potato improve nutrition a little. Children and women are still are at a nutritional disadvantage.
HEALTH PROFILE

Mortality Pattern

Disease Pattern

Disease Examples

Community Health Problems nutrition, childhood disease and maternal death, all aggravated by environmental problems (contaminated water and food, poor housing, insects, rodents) and lack of personal hygiene. There are no medical care systems and few decisive therapies. People have to rely on indigenous healing and witchcraft.
Life expectancy fluctuates around 20, and childhood mortality is very high: A third of all deaths occur in children from 0-5; 200-300 infant deaths occur per 1000 births and the neonatal to post-neonatal death ratio is small. Proportionate mortality for $50+$ ages is low since few reach that age. Females in the adolescent and reproductive years are at a higher risk of dying than males, but at lower risk at older ages. Mortality is somewhat higher in urban than in rural areas.

Leading causes of death and disease are the epidemic scourges, endemic, parasitic and deficiency diseases, pneumonia-diarrhea-malnutrition complex in children, and tuberculosis-puerperal-malnutrition complex in females. Manifest famines occur and severe malnutrition underlies disease and death from most other causes.

1) Tuberculosis is more virulent in young females, especially in their fertile years.

2) Smallpox is typically a childhood disease.

3) Heart disease rates are low, with high rheumatic to arteriosclerotic ratio.

4) Deficiency disease symptomatology is typical and highly prevalent.
Mortality remains high but shows signs of declining as fluctuations become less pronounced. Life expectancy increases to mid-20's and early $30^{\prime}$ s. Females are still at high risk of dying in the adolescent and fertile years. Infant and childhood mortality are high with small neonatal to post-neonatal ratio; proportionate mortality of the $50+$ ages increases somewhat. Urban mortality remains higher than rural.

Leading causes of death and disease are endemic, parasitic and deficiency diseases, epidemic scourges, childhood and maternal complexes. Industrial disease increases. Undernutrition, though somewhat ameliorated, continues to be important.

1) Tuberculosis mortality peaks with industrialization; it is still more virulent in young females.

2) Smallpox is still chiefly a disease of childhood.

3) Heart disease is still low, with a high rheumatic to arteriosclerotic ratio.

4) Death from starvation is less frequent but typical deficiency diseases still occur.

Epidemics, famine, undernutrition, childhood disease and maternal death are important, environmental problems persist, and industrial health problems emerge. There are no medical care systems and few decisive therapies; hospitals are seen as "death traps." People rely on indigenous systems of healing, but personal hygiene and nutrition begin to improve slowly. 


\section{AGE OF RECEDING PANDEMICS \\ LATE PHASE}

\section{AGE OF DEGENERATIVE}

AND MAN-MADE DISEASE

Mortality slowly but progressively declines from higher than to lower than 30/1000. Several decades after mortality declines, fertility starts to decline also. Population growth is explosive for most of this period.

The young dependency ratio goes up as the proportion of children in the population increases; there is a slight increase in the old dependency ratio. Improved female survival results in an excess of females. There is continued emigration to colonies, and a substantial increase in rural to urban migration, with concomitant growth of industrial centers.

"Take-off" to sustained economic growth can often be traced to sharp stimuli such as scientific discovery or political revolution which galvanize business and labor to reinforce gains in gross, real and per capita income through reinvestment and speculation.
Mortality declines rapidly to below 20/1000; then the rate of decline slows. Fertility declines to below 20/1000 (with occasional rises, e.g. the post-World War II baby boom) and becomes chief pace maker of population growth; fluctuation is by design more than by chance. Population growth is small but persistent.

There is a progressive aging of the population as fertility continues to decline and more people, especially females, survive to middle and old age. The male/female ratio continues to decrease. There is a high and increasing old dependency ratio, especially for women. Residence is increasingly urban, with excessive growth of cities (megalopolitanism) and alarming slum formation, environmental pollution, and unwieldy social and political problems.

Scientific expertise and applied technology covering the gamut of economic activities produce spiralling growth initially. Then a stage of high mass consumption brings tapered growth as production shifts from producer to consumer goods and services; public welfare and leisure spending increase.
An era of rising expectations touches nearly all segments of society.

Extended, large families persist in rural areas; nuclear families prevail increasingly in urban centers. Many women are employed in factories and become more involved in activities outside the home.

Hygiene and sanitation improve, except in city slums where bad conditions grow worse.

Continued improvements in agricultural technology guarantee better availability and quality of food.
Rational-purposive life styles prevail; bureaucracy and depersonalization foster anomic groups.

Nuclear families and small family size norms become institutionalized. Women are increasingly emancipated from traditional roles and become better educated and more career oriented.

Progressive rises in living conditions are enjoyed by large segments of the population.

People become extremely conscious of nutrition, especially that of children and mothers. There is, however, a tendency to over-nutrition including consumption of rich and high-fat foods which may increase the risk of heart and metabolic diseases.
There is considerable change in mortality level and pattern with the recession of pandemics. Life expectancy increases to 30 to $40+$. Mortality declines favor children under 15 and women in the fertile years. Infant mortality drops below 150/1000 births and the neonatal to post-neonatal ratio increases progressively. Proportionate mortality of the $50+$ ages increases to close to 50 per cent.

Pandemics of infection, malnutrition and childhood disease recede; plagues disappear. Cholera sweeps Europe in successive waves before disappearing. Infection remains the leading cause of death, but non-infectious diseases begin to be more significant.

1) Tuberculosis declines but there is still a slight excess in young females.

2) Smallpox starts to occur less in children and more in adults due to vaccination of children.

3) Heart disease increases, and there is a decrease in the rheumatic to arteriosclerotic ratio.

4) Death from starvation is rare, and many deficiency diseases such as scurvy start to disappear.

Epidemics and famines recede; childhood disease and maternal death decrease. Environmental control-e.g. water filtration, refuse pick-up-is started in cities. Health systems develop but are limited in scope. A few decisive therapies and prophylactic measures are devised. The importance of workers' health is recognized. Personal hygiene and nutrition improve.
Life expectancy reaches an unprecedented high of $70+$ and is about three or more years higher for women than for men. Risks for females of all ages decrease, and maternal mortality declines to a minimum. The age profile shows reductions in childhood mortality which account for less than 10 per cent of the total deaths, while deaths at $50+$ years increase to 70 per cent or more of the total. Infant mortality is less than $25 / 1000$ and the ratio of neonatal to post-neonatal deaths is large and still increasing.

Heart disease, cancer and stroke replace infection as prime killers. Pneumonia, bronchitis, influenza and some viral diseases remain problems. Polio rises, then tapers off. Scarlet fever starts to disappear.

1) Tuberculosis is low but persists in slum populations and in older disadvantaged individuals, especially males.

2) Smallpox is rare, and when it does occur, it is a disease of adults.

3) Heart disease is high, with a very low rheumatic to arteriosclerotic ratio.

4) Starvation is rare; pellagra disappears; rickets drops off.

Morbidity comes to overshadow mortality as an index of health as degenerative and chronic disease problems prevail and mental illness, addiction, accidents, radiation hazards and other pollution problems become more prevalent. More decisive therapies are available, and health systems gradually become oriented to preventive care and case-finding, although rising medical costs become a stubborn health problem. 


\section{REFERENCES}

${ }^{1}$ Mayer, K., Developments in the Study of Population, Social Research, 29, 292-320, Autumn, 1962.

2 See, for example, Van Nort, L. and Karon, B. P., Demographic Transition Re-examined, American Sociological Review, 20, 523-527, October, 1955; or Micklin, M., Urban Life and Differential Fertility: A Specification of the Theory of the Demographic Transition, presented at the annual meetings of the Population Association of America, Boston, April, 1968.

${ }^{3}$ United Nations Department of Social Affairs, Population Branch, Age and Sex Patterns of Mortality: Model Life Tables for Under-Developed Countries, Population Studies, No. 22, New York, United Nations, 1955.

4 Angel and Pearson, cited in Woytinsky, W. S. and Woytinsky, E. S., world POPULATION AND PRODUCTION: TRENDS AND OUTLOOK, New York, Twentieth Century Fund, 1953.

5 Russell, J. C., Late Ancient and Medieval Population, Transactions of the American Philosophical Society, 48, June, 1958, part 3.

6 Landis, P. H. and Hatt, P. K., POPUlation PRoblems: A CULTURAL INTERPRetation, New York, American Book Company, 1954.

7 Utterstrom, G., Two Essays on Population in Eighteenth Century Scandinavia, in Glass, D. V. and Eversley, D. E. C. (Editors), POPULATION IN HISTORY, Chicago, Aldine Publishing Company, 1965, pp. 523-548.

8 Eversley, D. E. C., A Survey of Population in an Area of Worcestershire from 1660 to 1850 on the Basis of Parish Registers, Population Studies, 10 253-279, 1957.

9 Chambers, J. D., Three Essays on the Population and Economy of the Midlands, in Glass and Eversley, op. cit., pp. 308-353.

10 Vielrose, Egon, elements of The NATURAL Movement of populations, Oxford, Pergamon Press, Inc., 1965.

11 Deprez, P., The Demographic Development of Flanders in the Eighteenth Century, in Glass and Eversley, op. cit., pp. 608-630.

12 Drake, M., POPUlation AND society IN NORWAy, 1735-1865, Cambridge, England, Cambridge University Press, 1969.

13 Reinhard, M., Armengaud, A. and Dupaquier, J., Histoire generale DE la population mondiale, Paris, Editions Montchrestien, 1968.

14 Graunt, J., NATURAL AND POLITICAL OBSERVATIONS MADE UPON THE BILLS of MORTALITY, Baltimore, The Johns Hopkins Press, 1939; this book was orginally published in London in 1662 .

15 Department of Economic and Social Affairs, Population Bulletin of the United Nations, No. 6, New York, United Nations, 1962, pp. 110-112.

16 McKeown, T. and Brown, R. G., Medical Evidence Related to English Population Change in the Eighteenth Century, Population Studies, 9, 119-141, 1955.

17 El-Badry, M. A., Higher Female Than Male Mortality in Some Countries of South Asia: A Digest, Journal of the American Statistical Association, 64, 1234-1244, December, 1969.

18 Ridley, J. C. et al., The Effects of Changing Mortality on Natality: Some Estimates from a Simulation Model, Milbank Memorial Fund Quarterly, 45, 77-97, January, 1967.

19 Heer, D. M., Births Necessary to Assure Desired Survivorship of Sons Under Differing Mortality Conditions, paper presented at the Annual Meeting of the Population Association of America, New York City, April, 1966.

20 Hassan, S., INFLUENCE OF GHILD MORTALITY ON POPUlation GROWTH, Ann Arbor, Michigan, University Microfilms, 1966.

21 Sauvy, A., general theory of POpulation, New York, Basic Books, Inc. Publishers, 1969.

22 Rostow, W. W., STAGES OF EGONOMIC GROWTH: AN ANTI-COMMUNIST manIfesto, New York, Cambridge University Press, 1960

\section{ACKNOWLEDGMENTS}

I want to express special thanks to Dr. John Cassel, Chairman of the Department of Epidemiology, School of Public Health, and to Dr. Moye Freyman, Director, Carolina Population Center, University of North Carolina, for their continuing support, valuable suggestions and constructive criticism throughout this project. Thanks also to Sandra Burden, social research assistant for her valuable contributions to this project; to Jeannette Cannon, Ann Herrin, Anita Leung, Çiçek Yener, statistical research assistants; to Cynthia Snow, editorial assistant; and to Libby Cline, secretary. 